\title{
Internet-Delivered Disease Management for Recurrent Depression: A Multicenter Randomized Controlled Trial
}

Kordy, Hans ; Wolf, Markus ; Aulich, Kai ; Bürgy, Martin ; Hegerl, Ulrich ; Hüsing, Johannes ; Puschner, Bernd ; Rummel-Kluge, Christine ; Vedder, Helmut ; Backenstrass, Matthias

\begin{abstract}
BACKGROUND Strategies to improve the life of patients suffering from recurrent major depression have a high relevance. This study examined the efficacy of 2 Internet-delivered augmentation strategies that aim to prolong symptom-free intervals. METHODS Efficacy was tested in a 3-arm, multicenter, open-label, evaluator-blind, randomized controlled trial. Upon discharge from inpatient mental health care, 232 adults with 3 or more major depressive episodes were randomized to 1 of 2 intervention groups (SUMMIT or SUMMIT-PERSON) or to treatment as usual (TAU) alone. Over 12 months, participants in both intervention arms received, in addition to TAU, intense monitoring via e-mail or a smartphone, including signaling of upcoming crises, assistance with personal crisis management, and facilitation of early intervention. SUMMIT-PERSON additionally offered regular expert chats. The primary outcome was 'well weeks', i.e. weeks with at most mild symptoms assessed by the Longitudinal Interval Follow-Up Evaluation, during 24 months after the index treatment. RESULTS SUMMIT compared to TAU reduced the time with an unwell status (OR 0.48; 95\% CI 0.23-0.98) through faster transitions from unwell to well (OR 1.44; 95\% CI 0.83-2.50) and slower transitions from well to unwell (OR 0.69; 95\% CI 0.44-1.09). Contrary to the hypothesis, SUMMIT-PERSON was not superior to either SUMMIT (OR $0.77 ; 95 \%$ CI $0.38-1.56$ ) or TAU (OR $0.62 ; 95 \%$ CI $0.31-1.24$ ). The efficacy of SUMMIT was strongest 8 months after the intervention. CONCLUSIONS The fully automated Internet-delivered augmentation strategy SUMMIT has the potential to improve TAU by reducing the lifelong burden of patients with recurrent depression. The fact that the effects wear off suggests a time-unlimited extension.
\end{abstract}

DOI: https://doi.org/10.1159/000441951

Posted at the Zurich Open Repository and Archive, University of Zurich

ZORA URL: https://doi.org/10.5167/uzh-128181

Journal Article

Published Version

Originally published at:

Kordy, Hans; Wolf, Markus; Aulich, Kai; Bürgy, Martin; Hegerl, Ulrich; Hüsing, Johannes; Puschner, Bernd; Rummel-Kluge, Christine; Vedder, Helmut; Backenstrass, Matthias (2016). Internet-Delivered Disease Management for Recurrent Depression: A Multicenter Randomized Controlled Trial. Psychotherapy and Psychosomatics, 85(2):91-98.

DOI: https://doi.org/10.1159/000441951 


\title{
Internet-Delivered Disease Management for Recurrent Depression: A Multicenter Randomized Controlled Trial
}

\author{
Hans Kordy ${ }^{a}$ Markus Wolfa Kai Aulich ${ }^{d}$ Martin Bürgy ${ }^{e}$ Ulrich Hegerl ${ }^{f}$ \\ Johannes Hüsing $^{b}$ Bernd Puschner ${ }^{g} \quad$ Christine Rummel-Kluge ${ }^{f}$ \\ Helmut Vedder ${ }^{\text {h }}$ Matthias Backenstrass ${ }^{c}$ \\ ${ }^{a}$ Center for Psychotherapy Research, ${ }^{b}$ Coordinating Center for Clinical Trials (KKS) Heidelberg, and ${ }^{\mathrm{c}}$ Department of \\ General Adult Psychiatry, University of Heidelberg, Heidelberg, ${ }^{d}$ Department and Policlinic for Psychiatry and \\ Psychotherapy, Ernst-Moritz-Arndt University Greifswald, Greifswald, ' Department of Psychiatry, Social Psychiatry,

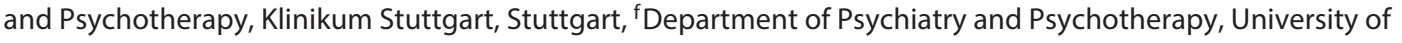 \\ Leipzig, Leipzig, ${ }^{9}$ Section Process-Outcome-Research, Department of Psychiatry II, Ulm University, Ulm, and \\ hDepartment of General Psychiatry, Psychotherapy, and Psychosomatics II, Psychiatric Center Nordbaden, \\ Wiesloch, Germany
}

\section{Key Words}

Efficacy · Disease management · Internet · Monitoring ·

Recurrent depression

\begin{abstract}
Background: Strategies to improve the life of patients suffering from recurrent major depression have a high relevance. This study examined the efficacy of 2 Internet-delivered augmentation strategies that aim to prolong symptom-free intervals. Methods: Efficacy was tested in a 3-arm, multicenter, open-label, evaluator-blind, randomized controlled trial. Upon discharge from inpatient mental health care, 232 adults with 3 or more major depressive episodes were randomized to 1 of 2 intervention groups (SUMMIT or SUMMIT-PERSON) or to treatment as usual (TAU) alone. Over 12 months, participants in both intervention arms received, in addition to TAU, intense monitoring via e-mail or a smartphone, including signaling of upcoming crises, as-
\end{abstract}

sistance with personal crisis management, and facilitation of early intervention. SUMMIT-PERSON additionally offered regular expert chats. The primary outcome was 'well weeks', i.e. weeks with at most mild symptoms assessed by the Longitudinal Interval Follow-Up Evaluation, during 24 months after the index treatment. Results: SUMMIT compared to TAU reduced the time with an unwell status (OR 0.48; 95\% $\mathrm{Cl} 0.23-0.98$ ) through faster transitions from unwell to well (OR 1.44; 95\% Cl 0.83-2.50) and slower transitions from well to unwell (OR $0.69 ; 95 \% \mathrm{Cl} 0.44-1.09)$. Contrary to the hypothesis, SUMMIT-PERSON was not superior to either SUMMIT (OR $0.77 ; 95 \% \mathrm{Cl} 0.38-1.56$ ) or TAU (OR $0.62 ; 95 \% \mathrm{CI}$ $0.31-1.24)$. The efficacy of SUMMIT was strongest 8 months after the intervention. Conclusions: The fully automated Internet-delivered augmentation strategy SUMMIT has the potential to improve TAU by reducing the lifelong burden of patients with recurrent depression. The fact that the effects wear off suggests a time-unlimited extension.

(c) 2016 S. Karger AG, Basel

\section{KARGER}

E-Mail karger@karger.com

www.karger.com/pps
(C) 2016 S. Karger AG, Basel

0033-3190/16/0852-0091\$39.50/0
Dr. Hans Kordy

Center for Psychotherapy Research

University of Heidelberg

Bergheimer Strasse 54, DE-69115 Heidelberg (Germany)

E-Mail hans.kordy@med.uni-heidelberg.de 
Recurrent major depressive disorder (MDD) reduces the quality of life of the affected individuals, their families, and social networks and causes significant economic losses for society [1-4]. The lifetime risk of relapse or recurrence following a single episode is estimated at $70 \%$, further increasing with succeeding episodes [5-7]. Relapse and recurrence are more likely if symptoms have not fully resolved during acute-phase treatment $[8,9]$.

Maintenance pharmacotherapy has become a key element in treatment guidelines [10-15]. Time-limited continuation and maintenance phase psychotherapies also appear promising for relapse prevention [16-24]. Specifically, continuation cognitive therapy and continuation phase fluoxetine were shown to reduce relapse over 8 months significantly more than a pill placebo in adults who responded to acute-phase cognitive therapy and had an elevated risk of relapse due to slow or incomplete remission in acute-phase cognitive therapy. After discontinuation of the continuation phase treatments, the rates of relapse/recurrence no longer differed from the rate of the pill placebo group [22]. Similarly, maintenance cognitive-behavioral therapy reduced the 1-year follow-up relapse rate to $50 \%$, compared to $73 \%$ for psychoeducation, in patients at a high risk for relapse due to more than 4 prior episodes [23]. These studies exemplify the need for strategic extensions of evidence-based treatments [25]. Although a considerable proportion of patients with recurrent depression may benefit, the majority will be confronted with a new episode. If they are not prepared for a possible negative course of their depression, patients may attribute this development to their own failure, which may affect their coping efforts. Inter- and intraindividually varying courses of the illness underline the need for flexible, individualized, longterm, and in many cases lifelong strategies $[26,27]$ with the aim of prolonging interepisode intervals and reducing the severity as well as the duration of newly recurring episodes.

Based on growing evidence that mental health services can be effectively delivered over the Internet [28-35], this project tested the efficacy of 2 versions of the individualized, Internet-delivered augmentation strategy SUMMIT (Supportive Monitoring and Depression Management over the Internet) for patients with recurrent depression after acute-phase psychiatric treatment. We investigated whether these strategies in addition to treatment as usual (TAU) increase the 'well time' (i.e. absence of or at most mild depressive symptoms) in comparison to TAU alone during 24 months after the index treatment. Previous studies have suggested that personal guidance can both enhance outcomes and reduce attrition rates, which amount to up to $80 \%$ in unguided Internet interventions $[29,35]$. Therefore, this study investigated the specific effect of the option of consulting a clinical expert (SUMMIT-PERSON) compared to the fully automated Internet-delivered intervention only (SUMMIT). Thus, this trial was designed to test the composed hypothesis of superiority of SUMMIT over TAU as well as of SUMMITPERSON over SUMMIT.

Stimulated by the finding that the preventive effects of continuation cognitive therapy and continuation phase fluoxetine weaken after discontinuation at about 8 months in high-risk cognitive therapy responders [22], we additionally examined the efficacy of the new Internet-delivered strategies 8 months after their termination, i.e. 20 months after the end of the index treatment.

\section{Methods}

Details of the design and methods have been published elsewhere [36]; the methods are briefly summarized here. This trial is registered in the German Clinical Trials Register (ID: DRKS00000435).

Study Design

This trial is a multicenter, parallel-group, randomized controlled trial with 2 intervention groups and 1 control group. Patients were recruited between June 2010 and March 2013 at 6 psychiatric departments in Germany. Eligible patients were assigned to 12 months of participation in Internet-delivered augmentations of TAU either (a) with (SUMMIT-PERSON) or (b) without personal guidance (SUMMIT) or (c) with TAU alone. This study was conducted in accordance with Good Clinical Practice guidelines. A data safety and monitoring board was established and adverse events (AE) were documented. The Coordinating Center for Clinical Trials of the University of Heidelberg provided independent study monitoring, the randomization list, and statistical analyses. The Ethics Committee of the Medical Faculty of the University of Heidelberg and the local Ethics Committees at the clinical sites approved the study protocol.

\section{Participants}

Patients were included if they met the diagnostic criteria for a recurrent MDD according to the Structured Clinical Interview for DSM-IV [37], with a history of at least 3 depressive episodes. Patients had to be 18-65 years old and to have Internet access. Exclusion criteria were: an acute suicide risk; a history of psychosis, bipolar disorder, or an organic brain disorder; a primary diagnosis of another DSM-IV axis I disorder; severe medical conditions; severe cognitive impairment; illiteracy, and insufficient fluency in the German language. Patients were screened for eligibility by clinical experts shortly after admission to inpatient treatment for their current acute depressive episode. After a complete description of the study had been provided to the subjects, written informed consent was obtained.
Kordy et al. 


\section{Randomization}

Patients were randomly assigned to 1 of the 3 study arms at a 1:1:1 allocation ratio by a centralized online procedure at hospital discharge. Randomization was stratified by the number of previous episodes $(2-3,4-7$, or $>7)$ and depression severity at the end of the index treatment (PSR: 1-2 or 3-4) using the Psychiatric Status Rating (PSR) of the Longitudinal Interval Follow-Up Evaluation (LIFE) [38]. To enhance concealment, site was not used for stratification.

\section{Interventions}

Treatment as Usual. All patients received the usual care recommended by the German national practice guidelines for recurrently depressed patients, including maintenance antidepressant medication and clinical management [15] (online suppl. table ST1; see www.karger.com/doi/10.1159/000441951 for all online suppl. material). Patients provided the name and address of their TAU practitioner, who then was informed of the patient's study participation. There were no restrictions on TAU treatments during this study.

Supplemental to TAU, patients received proactive preparation for recurrence of depressive symptoms through an individual crisis management plan (CMP) developed with the study site clinical expert shortly before randomization (see online suppl. table ST2 for examples). All patients had access to the project website with general trial information and emergency contacts.

The Internet-delivered augmentations (SUMMIT and SUMMIT-PERSON) aim to prolong euthymia by signaling upcoming crises, assisting the individual in personal crisis management, and facilitating early intervention if needed. Patients were offered a 12-month participation in 1 of 2 versions of Internet-delivered augmentation of TAU. Both versions were delivered through a site-specific, encrypted, username- and password-protected website.

In both strategies, patients were accompanied via e-mail and/ or smartphone for 12 months after the inpatient index treatment, aiming to strengthen self-management skills and empowerment [36]. Automated supportive monitoring based on the Brief Patient-Health Questionnaire (PHQ-9) [39] enabled patients to evaluate the course of their depression [40]. Online provision of the CMP allowed proactive coping with any upcoming crisis. Furthermore, an Internet discussion forum provided peer support (online suppl. table ST2).

Patients in the SUMMIT-PERSON group were additionally offered (a) monthly consultation group chats with a clinical expert and (b) one-on-one chat consultations with a clinical expert when the patient's monitoring signaled an upcoming crisis.

\section{Outcome Assessment and Blinding}

Primary Outcomes. 'Well' and 'unwell' weeks over 24 months as determined by the PSR of the LIFE [38] were the primary outcomes. Weeks with PSR $\leq 2$ were considered well weeks (symptoms mostly absent) and weeks with PSR $\geq 3$ were unwell weeks (at least mild symptoms). The ratio of well to unwell weeks was estimated by the ratio of transition rates from well to unwell, and back, which approximates the OR with respect to weeks between a well status and treatment conditions [36].

Trained interviewers conducted LIFE interviews every 6 months after randomization for a maximum of 24 months. The LIFE is a semi-structured interview and has proven to be a suitable measure for retrospective longitudinal assessments over periods of up to 24 months [38]. According to the study plan, the last patient enrolled was followed up for 12 months. Patients were censored after their last interview if they were observed for less than 24 months. LIFE interviews were conducted via a secured voice-overIP system to facilitate audio recording. Trained raters blinded to the study site and intervention group evaluated outcomes. Patients received a compensation of EUR 25 per interview.

\section{Adverse Events}

AE included any unfavorable medical events independently of a possible causal relation to the intervention. Serious AE (SAE) were defined as any life-threatening event or new or prolonged hospitalization. SAE were reported to and reviewed by the data and safety monitoring board.

\section{Statistical Analysis}

The trial biostatistician conducted statistical analyses using $\mathrm{R}$ software version 3.0.3. All analyses were intention to treat.

This trial was powered assuming a 0.8 relative risk of transition from well to unwell and a 1.25 relative chance of transition from unwell to well for SUMMIT compared to TAU, as well as for SUMMIT-PERSON compared to SUMMIT. Transitions were formulated as time-to-event models and analyzed by Cox proportional hazards regression models with multiple events per patient; a shared-frailty term was used for the patients [41, 42]. Intervention (SUMMIT, SUMMIT-PERSON), site, age (linear), sex, number of previous depression episodes (linear), and level of depressive symptoms (PSR, linear) at the end of the index treatment were used as explanatory variables. The global hypothesis of any effect was tested ( $\alpha=5 \%, 2$-tailed) via summing of the likelihood ratio test statistics for intervention in both the well and the unwell models and comparison with the 95th percentile of the central $\chi^{2}$ distribution with 4 degrees of freedom. Sensitivity analyses were conducted in the per protocol sample and under a best- and a worstcase scenario for the imputation of missing data. The Wald method was used to estimate the p values and $95 \%$ CI of specific contrasts.

\section{Results}

\section{Patient Flow}

Four hundred fifty-eight patients were screened for eligibility (fig. 1), and 222 (48\%) of these were excluded. Of the 236 eligible patients, 80 were randomized to TAU, 77 to SUMMIT, and 79 to SUMMIT-PERSON. Eight participants discontinued their study participation (TAU, $\mathrm{n}=5$; SUMMIT, $\mathrm{n}=3$ ), and 4 of these withdrew consent and requested deletion of their data (TAU, $\mathrm{n}=2$; SUMMIT, $\mathrm{n}=2$ ). This yielded an intention-to-treat sample of 232 participants. Seventeen participants could not be interviewed, and hence no PSR data were available on their symptom course during follow-up. One patient (TAU) was interviewed only once because his index treatment lasted 5.5 months. 


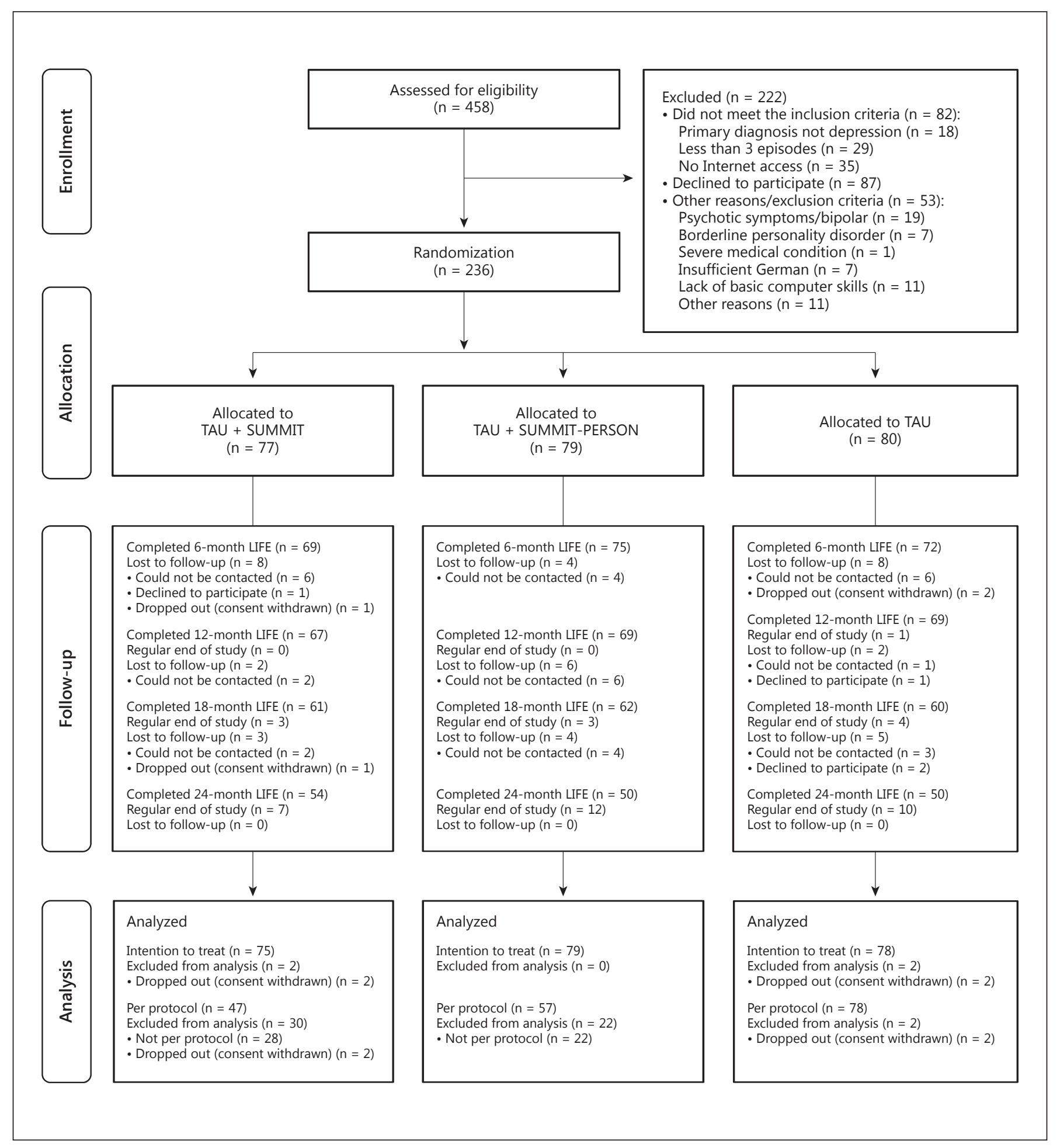

Fig. 1. CONSORT diagram. 


\section{Sample}

All patients were diagnosed with SCID-defined recurrent MDD. Half of the patients met the diagnostic criteria for one or more other DSM-IV axis I diagnoses, of which anxiety disorders were the most prevalent (online suppl. table ST3). Forty-two patients met the criteria for one or more axis II personality disorders. Fifty-seven patients reported prior suicide attempts and 10 were suicidal at the beginning of their index treatment. The current index inpatient treatment lasted 68.4 days (SD 41.2), on average.

On average, patients had experienced 5.6 (SD 3.7) lifetime depressive episodes prior to this study, and two thirds showed residual symptoms (PSR $>2$ ) upon clinical expert evaluation at hospital discharge (SUMMIT, 69\%; SUMMIT-PERSON, 62\%, and TAU, 63\%). Half of the patients experienced a relapse/recurrence within the 24-month observation period (SUMMIT, 51\%; SUMMIT-PERSON, 51\%, and TAU, 53\%; further details are available in online suppl. table ST3).

\section{Therapists and Treatment Integrity}

Patients in all 3 arms received TAU following German treatment guidelines [15]. Almost all patients (99\%) reported having received continuous outpatient treatment (online suppl. table ST1). One third was rehospitalized at least once during follow-up. Nearly all patients continuously took antidepressants, and about two thirds received additional psychotropic medication such as antipsychotics or mood stabilizers. Medical treatment did not differ across the 3 groups, with 1 exception: TAU-alone patients received additional psychotropic medication slightly more often (TAU, 74\%; SUMMIT, 65\%, and SUMMITPERSON, 55\%).

\section{Uptake of the Internet-Delivered Augmentation Strategies}

On average, patients completed two thirds of the monitoring assessments in both groups, i.e. SUMMIT (mean 68.9\%, SD 32.8, median 84\%) and SUMMITPERSON (mean 68.7\%, SD 34.6, median 84\%), over the 12 -month intervention. The CMP was accessed on average 3.7 times (further utilization details are available in online suppl. table ST4). Of the patients allocated to SUMMIT-PERSON, 15 (19\%) attended at least 1 monthly expert group chat. Due to the course of their symptoms, 57 patients were encouraged to consult the clinical expert in a one-on-one chat, which was utilized by 4 patients.

\section{Primary Outcome}

Half of the patients ( $\mathrm{n}=121 ; 52 \%)$ experienced at least 2 transitions of symptom status from well (PSR $\leq 2)$ to unwell (PSR >2) and back, or from unwell to well and back, during the follow-up period. The global hypothesis predicted an accumulated gain of well weeks through decelerated transitions from well to unwell and accelerated transitions from unwell to well for both Internet-delivered strategies compared to TAU alone, and for SUMMIT-PERSON compared to SUMMIT. The test of this composed global hypothesis was not significant $\left[\chi^{2}\right.$ $($ d.f. $=4) 5.29, \mathrm{p}=0.26]$.

Exploration of specific contrasts at the primary endpoint indicated the efficacy of SUMMIT compared to TAU alone (OR 0.48; 95\% CI 0.23-0.98; $\mathrm{p}=0.04$ ). This effect was composed of slower transitions from well to unwell (OR 0.69; 95\% CI 0.44-1.09; $\mathrm{p}=0.11$ ) and faster transitions from unwell to well (OR 1.44; 95\% CI $0.83-$ 2.50; $\mathrm{p}=0.19$; online suppl. table ST5). Comparison of SUMMIT-PERSON with TAU alone pointed in the same direction, but this did not reach statistical significance (OR 0.62; 95\% CI 0.31-1.24; $\mathrm{p}=0.18$ ). No substantial difference between SUMMIT and SUMMIT-PERSON emerged (OR 0.77; 95\% CI 0.38-1.56; $\mathrm{p}=0.47$; online suppl. table ST5).

For both Internet-delivered interventions, the effect on transition from unwell to well was strongest after the intervention, i.e. at the 12-month evaluation (SUMMITPERSON vs. TAU: OR 1.90; 95\% CI 1.06-3.41; $\mathrm{p}=0.03$; SUMMIT vs. TAU: OR 1.89; 95\% CI 1.04-3.44; $\mathrm{p}=0.04$ ), and weakened until the 24-month evaluation (online suppl. table ST5). The effect on transition from well to unwell peaked for SUMMIT at 20 months, i.e. 8 months after the intervention (OR 0.61; 95\% CI 0.37-1.00; $\mathrm{p}=$ 0.05 ), and weakened at the 24 -month evaluation (online suppl. table ST5).

The accumulated gains are illustrated by the median proportions of well weeks: $52 \%$ in SUMMIT and $48 \%$ in SUMMIT-PERSON versus $31 \%$ in TAU alone.

\section{Adverse Events}

One hundred sixty-nine AE were rated as serious according to prespecified criteria (mostly rehospitalizations due to worsening depressive symptoms or suicidal ideation). Events were equally distributed across the 3 study arms. Three patients had suicide attempts or committed serious self-injuries (SUMMIT, $\mathrm{n}=2$; TAU, $\mathrm{n}=1$ ). No fatal outcomes or deaths occurred during this trial. No participant was withdrawn from this study. 


\section{Discussion}

This treatment augmentation trial yielded promising yet ambiguous findings. A fully automated version of the Internet-delivered depression management strategy SUMMIT proved efficacious compared to TAU alone. Contrary to the prediction, SUMMIT-PERSON showed no benefit compared to either SUMMIT or TAU. This led to failure to reject the composed global null hypothesis testing the overall difference between the 3 groups. The main additional feature of SUMMIT-PERSON compared to SUMMIT was the patient's option to review their individual CMP together with a clinical expert in an online chat. Patients rarely used this option. Hence the additional benefit assumed in the power analysis proved unrealistic.

As hypothesized, the gains of SUMMIT accumulated over decelerated transitions from well to unwell and accelerated transitions from unwell to well. Together, the odds of unwell weeks were halved for SUMMIT compared to TAU alone. This size corresponds to the aim of improvement on which the power analysis was based. As this study was powered for the accumulated effect, it lacked power to reliably estimate the separate effects of the 2 directions of the transitions. However, the data point to a preventive effect (transitions from well to unwell) as well as to a crisis management effect (unwell to well) and invite further exploration. While the crisis management effect was strongest upon discontinuation of SUMMIT, the preventive effect peaked at 20 months, i.e. 8 months after discontinuation. These differential time patterns might be due to the fact that only one third of the patients started with a well status, while two thirds of the patients started with an unwell status, and the median time to change to well was 44 weeks in SUMMIT (vs. 55 weeks in TAU). SUMMIT-PERSON replicated these findings for the crisis management effect, which again was strongest upon discontinuation.

This study has several implications. First, for most patients with 3 or more depressive episodes the chance of recovery is small [18]. Therefore, an extension of well times is a highly relevant objective for mental health services. On average, patients receiving TAU alone could expect only 16 well weeks per year. The novel Internet-delivered augmentations promise meaningful clinical improvements through an increase to 27 (SUMMIT) and 25 (SUMMIT-PERSON) well weeks per year.

Second, a stable symptom course was exceptional. Two thirds of the patients started follow-up within an unwell status, and two thirds of these changed at least once to a well status during the observation period; 3 quarters of these changed back to an unwell status. Almost 3 quarters of the patients who started the postinpatient period with a well status changed at least once to unwell, and almost all of them returned to well. Furthermore, the observed rates of relapse/recurrence corresponded to those reported in the literature for this patient group [18-24]. This underscores the value of an adaptive strategy $[25,26]$ such as SUMMIT that has the capability of halving the odds for unwell times by both decelerating transitions from well to unwell and accelerating transitions from unwell to well.

Third, according to the literature, Internet-delivered interventions suffer from high attrition, which personal contact can reduce $[29,35]$. In our study, however, the dropout rate was low across all 3 arms (3\%). Thus, the additional personal-contact resources of SUMMIT-PERSON may not further augment under the conditions of the present study, where the Internet-delivered intervention was integrated into well-established mental health services. Specifically, continuous contact with the TAU clinician might have reduced the wish to contact an expert online. This suggests a need to place these novel services in the hands of TAU therapists to examine whether and how that may change utilization.

This study has several strengths. It includes a large sample of patients with recurrent depression and a high risk of relapse due to at least 3 episodes and a lack of full remission at the end of their index inpatient treatment.

This study aims beyond placebo beating. All patients received time-unlimited outpatient aftercare according to treatment guidelines (TAU), including antidepressant maintenance medication and clinical management. Thus, TAU represented a rather strong comparator, corresponding to the study objective of improving mental health services.

Augmentation of TAU with the novel Internet-delivered services provided after intense acute-phase treatment can be understood as an individualized sequential strategy $[26,27]$. Reinforcement of feedback during well phases and provision of an individualized CMP at times when symptoms are exacerbated are responses to the changing needs of the individual patient. The inclusion criteria and in-hospital recruitment limit the generalizability of the findings. Fully reimbursed hospital treatment - with an average duration of more than 2 months - is common practice in the German health care system. However, the high comorbidity, long illness histories, and prevalence of suicidality in our sample indicate that we may have selected sicker patients for this study through recruitment in hospitals. These specifics of the German health service system may make transla-
96

Psychother Psychosom 2016;85:91-98 DOI: $10.1159 / 000441951$
Kordy et al. 
tion to other countries with different health system conditions an open question.

In conclusion, the novel Internet-delivered service has the potential to reduce the lifelong burden of patients with recurrent depression. This clinical trial investigated a 12-month version of SUMMIT (and SUMMIT-PERSON) as a first step towards a lifelong individualized adaptive depression management strategy [18, 26, 27]. The crisis management effect on transitions from unwell to well, as well as the preventive effect, faded after discontinuation of the Internet-delivered services, which is a common observation in maintenance treatments [22, 23]. This invites testing of an open-ended provision to increase the durability of the effects. There is no financial reason for a time limit, because SUMMIT is fully automated. Most costs, such as for maintenance, are fixed. Variable costs emerge only through the introduction of the patient to the online system.

We can only speculate about what helped the patients and presume that the Internet-delivered services enhance patients' empowerment, their self-management skills, and particularly their capability for self-therapy [27, 43]. Patients do not expect the new Internet-delivered intervention to be a panacea (online suppl. table ST6). They learn to evaluate the course of their symptoms through supportive monitoring. They are encouraged to proactively cope with an upcoming crisis with the support of their CMP. This may reduce feelings of helplessness and strengthen the patient's understanding of being a partner of the TAU therapist. Ultimately, this might increase the patient's willingness to share responsibility for their depression management and thus to get more from it.

The utilization data demonstrated that both Internetdelivered management strategies were well accepted by the study participants. Unfortunately, we did not have the resources to systematically collect information on the view of the more than 200 TAU therapists involved in this study. However, none of them objected to their patients' participation in this study, which can be read as implicit acceptance. Therapists may be interested in sharing with their patients the continuous information provided through supportive monitoring for a better match between the care provided and the - changing - needs of the individual patient [25]. Together with the clinical benefits of the new services, this raises the hope that TAU therapists may be persuaded to join their patients in using this new individualized adaptive strategy in a future translational research project.

\section{Acknowledgement}

The authors gratefully acknowledge the patients for participation in this trial, and the staff and clinical experts of the participating centers for their efforts in participant screening, clinical assessments, and providing online consultations. The authors are especially grateful to the members of the Data Safety and Monitoring Board: Dr. Robin B. Jarrett, Dr. Fritz Hohagen, and Dr. Rainer Muche for their continuous support, and to Dr. Robin B. Jarrett, Dr. John C. Markowitz, and Dr. Charles F. Reynolds for their great help in making this report readable.

This study was funded by the German Research Foundation (Deutsche Forschungsgemeinschaft; grant KO-1109/19-1).

\section{Disclosure Statement}

Within the last 3 years, Dr. Hegerl has been an advisory board member for Lilly, Lundbeck, Takeda Pharmaceuticals, Servier, and Otsuka Pharma, and a speaker for Bristol-Myers Squibb, Medice Arzneimittel, Novartis. and Roche Pharma. Dr. Rummel-Kluge has received speaker honoraria from Janssen-Cilag. Dr. Vedder has received honoraria from Otsuka Pharma for services in an advisory board. Dr. Kordy, Dr. Wolf, Dr. Aulich, Dr. Bürgy, Dr. Hüsing, Dr. Puschner, and Dr. Backenstrass report no financial relationships with commercial interests.

\section{References}

1 World Health Organization: Strengthening Mental Health Promotion (Fact Sheet No 220). Geneva, World Health Organization, 2001.

2 Wittchen HU, Jacobi F, Rehm J, Gustavsson A, Svensson M, Jönsson B, Olesen J, Allgulander C, Alonso J, Faravelli C, Fratiglioni L, Jennum P, Lieb R, Maercker A, van Os J, Preisig M, Salvador-Carulla L, Simon R, Steinhausen HC: The size and burden of mental disorders and other disorders of the brain in Europe 2010. Eur Neuropsychopharmacol 2011;21:655679 .
3 ten Doesschate MC, Koeter MWJ, Bockting CLH, Schene AH; DELTA Study Group: Health-related quality of life in recurrent depression: a comparison with a general population sample. J Affect Disord 2010;120:126132.

4 Sobocki P, Jönsson B, Angst J, Rehnberg C: Cost of depression in Europe. J Mental Health Policy Econ 2006;9:87-98.

5 Angst J: Fortnightly review: a regular review of the long-term follow up of depression. BMJ 1997;315:1143-1146
6 Frank E, Thase ME: Natural history and preventative treatment of recurrent mood disorders. Annu Rev Med 1999;50:453-468.

7 Solomon DA, Keller MB, Leon AC, Mueller TI, Lavori PW, Shea MT, Coryell W, Warshaw M, Turvey C, Maser JD, Endicott J: Multiple recurrences of major depressive disorder. Am J Psychiatry 2000;157:329-333.

8 Hardeveld F, Sijker J, De Graaf R, Nolen WA, Beekman ATF: Prevalence and predictors of recurrence of major depressive disorder in the adult population. Acta Psychiatr Scand 2010; 122:184-191. 
9 Judd LL, Paulus MJ, Schettler PJ, Akiskal HS, Endicott J, Leon AC, Maser JD, Mueller T, Solomon DA, Keller MB: Does incomplete recovery from first lifetime major depressive episode herald a chronic course of illness? Am J Psychiatry 2000;157:1501-1504.

10 Jarrett RB, Kraft D, Doyle J, Foster BM, Eaves GG, Silver PC: Preventing recurrent depression using cognitive therapy with and without a continuation phase: a randomized clinical trial. Arch Gen Psychiatry 2001;58:381-388.

11 Frank E, Kupfer DJ, Perel JM, Cornes C, Jarrett $\mathrm{DB}$, Mallinger AG, Thase ME, McEachran AB, Grochocinski VJ: Three-year outcomes for maintenance therapies in recurrent depression. Arch Gen Psychiatry 1990;47:1093-1099.

12 Dew MA, White EM, Lenze EJ, Houck PR, Mulsant BH, Pollock BG, Stack JA, Bensasi S, Reynolds CF: Recovery from major depression in older adults receiving augmentation of antidepressant pharmacotherapy. Am J Psychiatry 2007; 164:892-899.

13 Keller MB: Past, present, and future directions for defining optimal treatment outcome in depression: remission and beyond. JAMA 2003; 289:3152-3160.

14 American Psychiatric Association: Practice Guideline for the Treatment of Patients with Major Depressive Disorder, ed 3. Arlington, American Psychiatric Association, 2010.

15 Deutsche Gesellschaft für Psychiatrie und Psychotherapie, Psychosomatik und Nervenheilkunde; Bundesarbeitsgemeinschaft für psychosoziale Krebsberatungsstellen; Kassenärztliche Bundesvereinigung; Arbeitsgemeinschaft der Wissenschaftlichen Medizinischen Fachgesellschaften (eds): Nationale Versorgungsleitlinie: unipolare Depression. Berlin, Springer, 2010.

16 Frank E, Kupfer DJ, Buysse DJ, Swartz HA, Pilkonis PA, Houck PR, Rucci P, Novick DM, Grochocinski VJ, Stapf DM: Randomized trial of weekly, twice-monthly, and monthly interpersonal psychotherapy as maintenance treatment for women with recurrent depression. Am J Psychiatry 2007;164:761-767.

17 Vittengl JR, Clark LA, Dunn TW, Jarrett RB: Reducing relapse and recurrence in unipolar depression: a comparative meta-analysis of cognitive-behavioral therapy's effects. J Consult Clin Psychol 2007;75:475-488.

18 Bockting CL, Hollon SD, Jarrett RB, Kuyken W, Dobson K: A lifetime approach to major depressive disorder: the contribution of psychological interventions in preventing relapse and recurrence. Clin Psychol Rev 2015;41:16-26.

19 Hollon SD, DeRubeis RJ, Shelton RC, Amsterdam JD, Salomon RM, O’Reardon JP, Lovett ML, Young PR, Haman KL, Freeman BB, Gallop R: Prevention of relapse following cognitive therapy vs. medications in moderate to severe depression. Arch Gen Psychiatry 2005;62: 417-422.

20 Fava GA, Ruini C, Rafanelli C, Finos L, Conti S, Grandi S: Six-year outcome of cognitive behavior therapy for prevention of recurrent de- pression. Am J Psychiatry 2004;161:18721876.

21 Bockting CL, Schene AH, Spinhoven P, Koeter MW, Wouters LF, Huyser J, Kamphuis JH: Preventing relapse/recurrence in recurrent depression with cognitive therapy: a randomised controlled trial. J Consult Clin Psychol 2005; 73:647-657.

22 Jarrett RB, Minhajuddin A, Gershenfeld H, Friedman ES, Thase ME: Preventing depressive relapse and recurrence in higher-risk cognitive therapy responders: a randomized trial of continuation phase cognitive therapy, fluoxetine, or matched pill placebo. JAMA Psychiatry 2013;70:1152-1160.

23 Stangier U, Hilling C, Heidenreich T, Risch AK, Barocka A, Schlösser R, Kronfeld K, Ruckes C, Berger H, Röschke J, Weck F, Volk S, Hambrecht M, Serfling R, Erkwoh R, Stirn A, Sobanski T, Hautzinger M: Maintenance cognitive-behavioral therapy and manualized psychoeducation in the treatment of recurrent depression: a multicenter prospective randomized controlled trial. Am J Psychiatry 2013;170: 624-632.

24 Kuyken W, Hayes R, Barrett B, Byng R, Dalgleish T, Kessler D, Lewis G, Watkins E, Brejcha C, Cardy J, Causley A, Cowderoy S, Evans A, Gradinger F, Kaur S, Lanham P, Morant N, Richards J, Shah P, Sutton H, Vicary R, Weaver A, Wilks J, Williams M, Taylor RS, Byford S: Effectiveness and cost-effectiveness of mindfulness-based cognitive therapy compared with maintenance antidepressant treatment in the prevention of depressive relapse or recurrence (PREVENT): a randomised controlled trial. Lancet 2015;386:63-73.

25 Fava GA, Guidi J, Rafanelli C, Sonino N: The clinical inadequacy of evidence-based medicine and the need for a conceptual framework based on clinical judgement. Psychother Psychosom 2015;84:1-3.

26 Lavori PW, Dawson R: Adaptive treatment strategies in chronic disease. Annu Rev Med 2008;59:443-453.

27 Fava GA, Tomba E, Grandi S: A road to recovery from depression - don't drive today with yesterday's map. Psychother Psychosom 2007; 76:260-265.

28 Golkaramnay V, Bauer S, Haug S, Wolf M, Kordy H: The exploration of the effectiveness of group therapy through an Internet chat as aftercare: a controlled naturalistic study. Psychother Psychosom 2007;76:219-225.

29 Spek V, Cuijpers P, Nyklícek I, Riper H, Keyzer J, Pop V: Internet-based cognitive behavior therapy for symptoms of depression and anxiety: a meta-analysis. Psychol Med 2007;37: 319-328.

30 Mackinnon A, Griffiths KM, Christensen H: Comparative randomised trial of online cognitive-behavioural therapy and an information website for depression: 12-month outcomes. Br J Psychiatry 2008;192:130-134.

31 Kessler D, Lewis G, Kaur S, Wiles N, King M, Weich S, Sharp DJ, Araya R, Hollinghurst S,
Peters TJ: Therapist-delivered Internet psychotherapy for depression in primary care: a randomised controlled trial. Lancet 2009;374: 628-634.

32 Andrews G, Cuijpers P, Craske MG, McEvoy $\mathrm{P}$, Titov N: Computer therapy for the anxiety and depressive disorders is effective, acceptable and practical health care: a meta-analysis. PLoS One 2010;5:e13196.

33 Andersson G, Cuijpers P: Internet-based and other computerized psychological treatments for adult depression: a meta-analysis. Cogn Behav Ther 2009;38:196-205.

34 Wiersma JE, Titov N, Van Schaik DJ, Van Oppen P, Beekman AT, Cuijpers P, Andrews GA: Treating chronic symptoms of depression in the virtual clinic: findings on chronicity of depression in patients treated with Internetbased computerized cognitive behaviour therapy for depression. Psychother Psychosom 2011;80:313-315.

35 Johansson R, Andersson G: Internet-based psychological treatments for depression. Expert Rev Neurother 2012;12:861-869.

36 Kordy H, Backenstrass M, Hüsing J, Wolf $M$, Aulich K, Bürgy M, Puschner B, RummelKluge C, Vedder H: Supportive monitoring and disease management through the Internet: an Internet-delivered intervention strategy for recurrent depression. Contemp Clin Trials 2013;36:327-337.

37 Wittchen H-U, Zaudig M, Fydrich T: SKID Strukturiertes klinisches Interview für DSMIV - Achse I und II. Handanweisung. Göttingen, Hogrefe, 1997.

38 Keller MB, Lavori PW, Friedman B, Nielsen E, Endicott J, McDonald-Scott P, Andreasen NC: The Longitudinal Interval Follow-up Evaluation: a comprehensive method for assessing outcome in prospective longitudinal studies. Arch Gen Psychiatry 1987;44:540-548.

39 Spitzer RL, Kroenke K, Williams JB; Patient Health Questionnaire Primary Care Study Group: Validation and utility of a self-report version of PRIME-MD: the PHQ primary care study. JAMA 1999;282:1737-1744

40 Bauer S, Okon E, Meermann R, Kordy H: Technology-enhanced maintenance of treatment outcome in eating disorders: efficacy of an intervention delivered via text messaging. J Consult Clin Psychol 2012;80:700-706.

41 Andersen PK, Keiding N: Multi-state models for event history analysis. Stat Methods Med Res 2002;11:91-115.

42 Salazar JC, Schmitt FA, Yu L, Mendiondo MM, Kryscio RJ: Shared random effects analysis of multi-state Markov models: application to a longitudinal study of transitions to dementia. Stat Med 2007;26:568-580.

43 Kok G, Burger H, Riper H, Cuijpers P, Dekker J, van Marwijk H, Smit F, Beck A, Bockting CLH: The three month effect of mobile Internet-based cognitive therapy on the course of depressive symptoms in remitted recurrently patients: results of a randomised trial. Psychother Psychosom 2015;84:90-99. 


\section{Supplementary Materials}

Table ST1. Utilization of psychiatric services, psychotherapy, and psychotropic medication in the three study groups during follow-up

\begin{tabular}{|c|c|c|c|}
\hline & $\begin{array}{l}\text { SUMMIT } \\
(\mathrm{N}=68)\end{array}$ & $\begin{array}{l}\text { SUMMIT-PERSON } \\
(\mathrm{N}=75)\end{array}$ & $\begin{array}{c}\text { TAU } \\
(\mathrm{N}=72)\end{array}$ \\
\hline Hospital treatment $(\mathrm{HO})$ & $34(50.0)$ & $23(30.7)$ & $28(38.9)$ \\
\hline Any outpatient treatment & $67(98.5)$ & 74 (98.7) & $71(98.6)$ \\
\hline Outpatient psychiatrist (OP) & $62(91.2)$ & $65(86.7)$ & $65(90.3)$ \\
\hline General practice $^{\mathrm{a}}(\mathrm{GP})$ & $17(25.0)$ & $14(18.7)$ & $12(16.7)$ \\
\hline Psychotherapy $^{\mathrm{b}}(\mathrm{PT})$ & $41(60.3)$ & $46(61.3)$ & $45(62.5)$ \\
\hline \multicolumn{4}{|l|}{ Treatment combinations } \\
\hline OP/GP/PT + HO & $34(50.0)$ & $23(30.7)$ & $28(38.9)$ \\
\hline $\mathrm{OP} / \mathrm{GP}+\mathrm{PT}$ & $18(26.5)$ & $29(38.7)$ & $26(36.1)$ \\
\hline OP/GP only & $14(20.6)$ & $21(28.0)$ & $15(20.8)$ \\
\hline PT only & $1(1.5)$ & $1(1.3)$ & $2(2.8)$ \\
\hline HO only & $0(0.0)$ & $0(0.0)$ & $0(0.0)$ \\
\hline $\begin{array}{l}\text { At least one outpatient (OP or GP) visit } \\
\text { each quartal of FU' }\end{array}$ & $44(64.7)$ & $49(65.3)$ & $49(68.1)$ \\
\hline Percent weeks of FU hospitalized & $12.26 \pm 12.94 ; 6.7$ & $11.87 \pm 6.83 ; 10.5$ & $14.10 \pm 8.24 ; 14.1$ \\
\hline $\begin{array}{l}\text { Percent weeks of FU any psychiatric in- or } \\
\text { outpatient treatment received }\end{array}$ & $93.00 \pm 18.85 ; 100$ & $89.27 \pm 22.09 ; 100$ & $91.11 \pm 22.03 ; 100$ \\
\hline Antidepressant medication & $64(94.1)$ & $73(97.3)$ & $68(94.4)$ \\
\hline Other psychotropic medication & $44(64.7)$ & $41(54.7)$ & $53(73.6)$ \\
\hline Antipsychotic & $34(50.0)$ & $38(50.7)$ & $45(62.5)$ \\
\hline Hypnotic/ Sedative/ Anxiolytic & $13(19.1)$ & $12(16.0)$ & $18(25.0)$ \\
\hline Mood stabilizer (Lithium, Anticonvulsive) & $15(22.1)$ & $11(14.4)$ & $21(29.2)$ \\
\hline No AD or psychotropic medication & $2(2.9)$ & $2(2.7)$ & $1(1.4)$ \\
\hline Percent weeks with $\mathrm{AD}$ medication & $89.0 \pm 24.1 ; 100$ & $85.9 \pm 21.8 ; 99$ & $84.9 \pm 27.8 ; 100$ \\
\hline
\end{tabular}

Notes: The table presents means \pm SD followed by median, and numbers (with \%). ${ }^{a}$ Only visits counted that were related to the depressive disorder (i.e., drug prescription or drug monitoring). ${ }^{\mathrm{b}}$ Only psychotherapies counted which were reimbursed by private or statutory health insurance with more than five sessions conducted (note that in order to receive reimbursement up to five probatory sessions have to be conducted before regular outpatient psychotherapy, usually individual or group CBT or psychodynamic psychotherapy, can be uptaken). ${ }^{\mathrm{c}}$ Quarterly visits for drug monitoring are standard in German health insurance coverage for patients receiving antidepressant medication. AD=Antidepressant. FU=Followup. 
Table ST2: Two Internet-delivered augmentation strategies - a brief summary and examples

\section{Overview:}

The Internet-delivered strategies SUMMIT and SUMMIT-PERSON consist of the following modules: (1) Information on depression and psycho-educational contents; (2) a supportive monitoring and feedback tool to enable the participant to track and evaluate the course of depressive symptoms; (3) an Internet discussion forum for peer support; (4) an individual crisis management plan to facilitate help seeking in an arising crisis. In addition, participants in the SUMMIT-PERSON group were offered (5a) monthly scheduled consultation group chats with a clinical expert, and (5b), one-on-one chat consultations with a clinical expert when the participant's monitoring is signaling an upcoming crisis.

\section{SUMMIT and SUMMIT-PERSON:}

\section{1.) Information and psycho-education}

The project website provides information on depressive disorders, e.g. epidemiology, causes and risk factors, early signs and symptoms, illness course, treatment, and relapse prevention.

2.) Supportive monitoring

Every two weeks, participants receive an email and/or text message with a link to the monitoring. In case of nonresponse, up to three reminders are automatically sent by email and text message within the next two days. The monitoring comprises nine items of the depression module of the Brief Patient Health Questionnaire (PHQ-9; [39]) and two items on current medication and treatment.

A software algorithm evaluates the status report, relates it to the report of the previous week, and sends a pre-specified feedback message via email and/or mobile (see Figure on the right hand side).

Feedback is based on two principles, reinforcement of positive developments and suggesting alternative behaviors in case of negative developments.

The monitoring generates a "signal" if the PHQ-9 scores $>9$. In that case, the participant is referred to his or

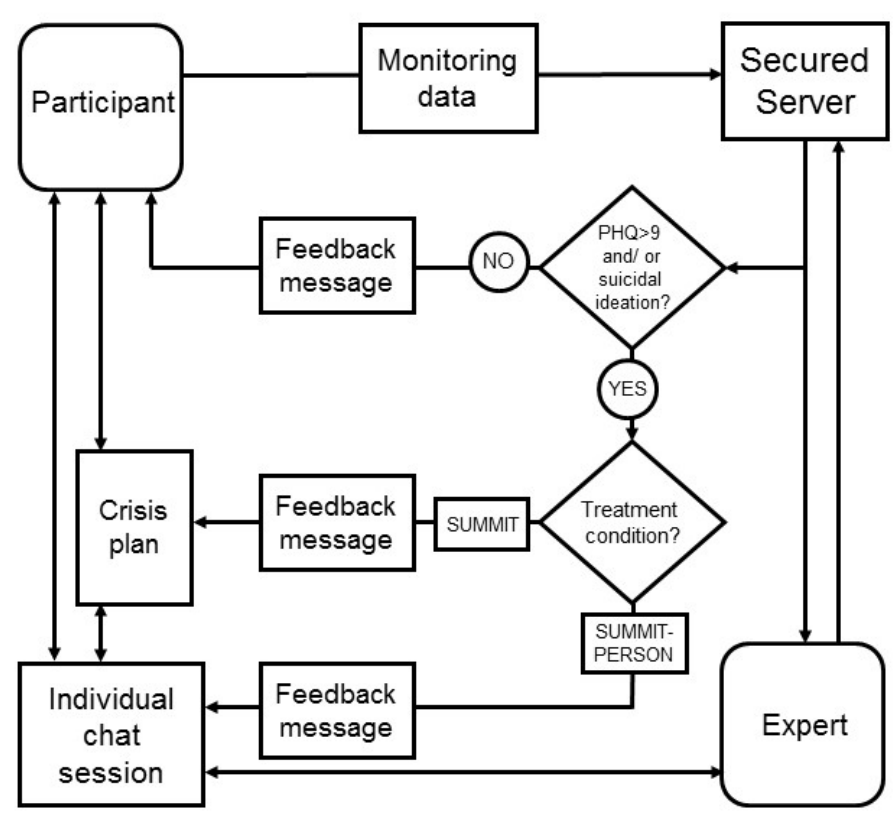
her crisis management plan. If the participant reports suicidal ideation, the feedback message prompts the participant to consult his or her TAU therapist. 
Table ST2 continued

3.) Internet discussion forum
An online discussion forum provides social support through sharing information and
personal experiences with other participants in similar situations. The forum is moderated
and monitored by a member of the research team in order to control for inappropriate
content.
4.) Individual crisis management plan (CMP)
Each participant (TAU included) developed his or her personal CMP together with the
clinical expert at the end of the index treatment. Any topic of personal significance in terms
of self-management, coping and relapse prevention, and related medical or psychosocial
treatment issues can be addressed and included in the CMP (see examples below).

\section{SUMMIT-PERSON:}

5a.) Monthly expert group chat

Participants in the SUMMIT-PERSON group are invited to meet with a clinical expert in an internet chat room on a monthly basis to address questions about depression and treatment. The expert chat takes place in the evening and lasts for 60 minutes. Participants are free to enter and leave the chat room at any time, to post their questions, or just follow the communication.

5b.) Individual chat consultation

In case the monitoring generates a signal (PHQ-9 $>9$ and/or self-reported suicidal ideation), the participant is encouraged to go online and book a chat session with one of the clinical experts to work through the individual CMP. The clinical expert has online access to the recorded history of the participant in the program, specifically the course of symptoms.

\section{Examples of an individual crisis management plan (CMP):}

\section{Example \#1:}

- When I feel bad, I will contact my doctor NN (Phone: xxxx).

- When I notice a change to the worse, together with my doctor NN, I will seek for a way to avoid further deterioration. I know that I always can call the psychiatric unit in an emergency situation (Phone: $\mathrm{xxxx}$ ).

- When I feel uncertain about my antidepressants or potential side effects I always can consult doctor NN. We will speak about possible dosage adjustments if appropriate.

- In critical situations I'll try out what helped me in previous critical situations:

- To go running daily: I am aware that it will be not easy for me to go running when I do not feel well. But I also know, that it will make me feel much better after 3-4 days.

- Go spend time with friends: Although I know that usually I do not want to see anybody in these situations, I do know that it will make me feel better if I manage to go out and meet friends.

- Listening to loud music when I feel restless.

- Surfing online, doing sports, or watching TV, when I need to stop ongoing rumination. 
Table ST2 continued

- Avoiding to spend too much time home alone: I have learnt that retreating into my own shell is not good for me.

- To take early warning signs serious: Critical situations often start with feelings of restlessness. Speaking to friends, doing sports, listening to loud music, have helped in the past to avoid manifestations of a crisis, and I'll try it again.

- If the idea will come up that I am better off dead, I'll call my doctor NN. If she will not be available I'll call the psychiatric hospital. I'll think about the people I would leave behind, and about how much the relationship with them means to me.

\section{Example \#2:}

I will say to myself:

- 15 minutes sports a day means doing something good for yourself. If you do this every day, then you will feel the success on your mood soon.

- Allow yourself something good and enjoyable. Change your hairstyling. Be flexible. Laughing does good. Meet with $\mathrm{K}$ for a coffee or go for bowling. Take time for yourself and call friends such as $\mathrm{H}$, or B, or M. Look into the future positively.

- Alone you may feel sad. You can call P anytime, and you can tell him how you feel. He knows you well and he will understand you. Talking can help. You are not alone.

- Reading and knitting interrupts your sad mood. Try it out; it will help you to get new energy.

- Say "No" without being conscience-stricken.

- If you get restless, and you are teared up, then play "Mahjong" or a similar computer game. Also crocheting will calm you down. Make concrete plans, than you have a goal you can pursue. That helps to overcome sad thoughts.

- Apathy is bullshit. It is unbearable when you feel listless. Go out for a walk or a cycling tour. Fresh air is good for you. Make no excuses. It will be to your best.

- When you realize that you are withdrawing from everything; when you realize, that everything is too much for you, than you are at high risk for further deterioration. Meeting and talking with $\mathrm{G}$ or $\mathrm{T}$ can help. Call them. Make an appointment!

- If all these options do not help, desperation may arise. However, it is not your fault, you tried everything. But now you need professional help. Consult Dr NN and ask for help and advice.

- If you feel absolutely hopeless and you can no longer think clearly, if you feel useless, if you think to harm yourself, then come to the psychiatric unit immediately. Don't hesitate! 
Table ST3: Demographic and clinical characteristics of the study patients

\begin{tabular}{|c|c|c|c|}
\hline Characteristic & $\begin{array}{l}\text { SUMMIT } \\
(\mathrm{N}=75)\end{array}$ & $\begin{array}{c}\text { SUMMIT- } \\
\text { PERSON } \\
(\mathrm{N}=79)\end{array}$ & $\begin{array}{c}\text { TAU } \\
(\mathrm{N}=78)\end{array}$ \\
\hline Age, years & $43.63 \pm 11.40$ & $40.04 \pm 10.24$ & $41.81 \pm 10.37$ \\
\hline Female gender & $38(50.7)$ & $42(53.2)$ & $49(62.8)$ \\
\hline \multicolumn{4}{|l|}{ Marital status } \\
\hline Married/cohabitating & $39(52.0)$ & $34(43.0)$ & $33(42.3)$ \\
\hline Divorced/ separated/ widowed & $13(17.3)$ & $15(19.0)$ & $23(29.5)$ \\
\hline Never married & $23(30.7)$ & $30(38.0)$ & $22(28.2)$ \\
\hline \multicolumn{4}{|l|}{ Education } \\
\hline High school diploma (12 years) & $47(62.7)$ & $47(59.5)$ & $45(57.7)$ \\
\hline Intermediate ( 10 years) & $17(22.7)$ & $20(25.3)$ & $11(14.1)$ \\
\hline Low (8 years) & $7(9.3)$ & $10(12.7)$ & $20(25.6)$ \\
\hline Other & $4(5.3)$ & $2(2.6)$ & $2(2.6)$ \\
\hline \multicolumn{4}{|l|}{ Employment status } \\
\hline Working full-time & $28(37.3)$ & $26(32.9)$ & $31(39.7)$ \\
\hline Working part-time & $15(20.0)$ & $14(17.7)$ & $13(16.7)$ \\
\hline Unemployed & $17(22.7)$ & $15(19.0)$ & $12(15.4)$ \\
\hline Other (Student, retired, parental leave) & $15(20.0)$ & $24(30.4)$ & $22(28.2)$ \\
\hline Age at MDD onset, years & $29.55 \pm 12.06$ & $25.27 \pm 10.46$ & $26.62 \pm 10.41$ \\
\hline Number of MDD episodes & $5.55 \pm 3.86$ & $5.61 \pm 3.74$ & $5.73 \pm 3.69$ \\
\hline Duration of index treatment, days & $68.21 \pm 40.26$ & $66.49 \pm 41.12$ & $70.51 \pm 42.64$ \\
\hline \multicolumn{4}{|l|}{ PSR at begin of index treatment } \\
\hline $1-2$ & $1(1.3)$ & $1(1.3)$ & $1(1.3)$ \\
\hline $3-4$ & $16(21.3)$ & $19(24.1)$ & $25(32.1)$ \\
\hline $5-6$ & $58(77.3)$ & $59(74.7)$ & $52(55.7)$ \\
\hline \multicolumn{4}{|l|}{ PSR at randomization } \\
\hline $1-2$ & $23(30.7)$ & $30(38.0)$ & $29(37.2)$ \\
\hline $3-4$ & $52(69.3)$ & $49(62.0)$ & $49(62.8)$ \\
\hline $5-6$ & $0(0.0)$ & $0(0.0)$ & $0(0.0)$ \\
\hline \multicolumn{4}{|l|}{ Suicidality at begin of index treatment } \\
\hline None & $54(72.0)$ & $52(65.8)$ & $59(75.6)$ \\
\hline Past & $17(22.7)$ & $22(27.8)$ & $18(23.1)$ \\
\hline Current & $4(5.3)$ & $5(6.3)$ & $1(1.3)$ \\
\hline Any Axis-I comorbidity ${ }^{a}$ & $39(52.0)$ & $36(45.6)$ & $39(50.0)$ \\
\hline \multicolumn{4}{|l|}{ Comorbid Axis-I diagnoses ${ }^{b}$} \\
\hline Anxiety & $30(40.0)$ & $30(38.0)$ & $32(41.0)$ \\
\hline Alcohol/ substance & $8(10.7)$ & $7(8.9)$ & $4(5.1)$ \\
\hline Other & $11(14.7)$ & $9(11.4)$ & $10(12.8)$ \\
\hline Any Axis-II comorbidity ${ }^{\mathrm{c}}$ & $14(18.7)$ & $13(16.5)$ & $15(19.2)$ \\
\hline
\end{tabular}

Table continued on next page. 
Table ST3 continued

\begin{tabular}{lccc}
\hline Characteristic & $\begin{array}{c}\text { SUMMIT } \\
(\mathrm{N}=75)\end{array}$ & $\begin{array}{c}\text { SUMMIT- } \\
\text { PERSON } \\
(\mathrm{N}=79)\end{array}$ & $\begin{array}{c}\text { TAU } \\
(\mathrm{N}=78)\end{array}$ \\
\hline Relapse/recurrence & & & \\
At 12-month FU & $33 / 75(44.0)$ & $34 / 79(43.0)$ & $33 / 78(42.3)$ \\
At 24-month FU & $38 / 75(50.7)$ & $40 / 79(50.6)$ & $41 / 78(52.6)$ \\
$\quad$ Without residual symptoms & $6 / 23(26.1)$ & $9 / 30(30.0)$ & $12 / 29(41.2)$ \\
$\quad$ With residual symptoms & $32 / 52(61.5)$ & $31 / 49(63.3)$ & $29 / 49(59.2)$ \\
$\quad$ Fewer than 5 previous episodes & $20 / 42(47.5)$ & $18 / 41(43.9)$ & $16 / 37(48.6)$ \\
5 or more previous episodes & $18 / 33(54.5)$ & $22 / 38(57.9)$ & $23 / 41(56.1)$ \\
\hline
\end{tabular}

Note: The table presents means $\pm \mathrm{SD}$, and numbers (with \%). MDD=Major depressive disorder;

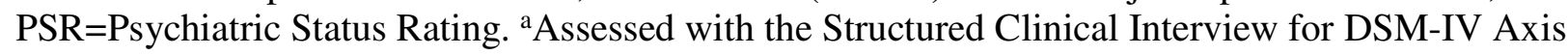
I (SCID-I). ${ }^{b}$ Patients could have more than one comorbid diagnosis. ${ }^{c}$ Assessed with the Structured Clinical Interview for DSM-IV Axis II, Personality Disorders (SCID-II). ${ }^{\mathrm{d}}$ Relapse/recurrence was defined as symptoms meeting DSM-IV criteria for MDD (PSR $\geq 5$ for 2 consecutive weeks of

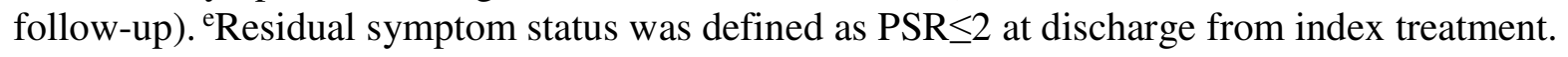


Table ST4. Program usage in the two intervention groups SUMMIT and SUMMIT-PERSON

\begin{tabular}{|c|c|c|}
\hline & $\begin{array}{l}\text { SUMMIT } \\
(\mathrm{N}=75)\end{array}$ & $\begin{array}{l}\text { SUMMIT-PERSON } \\
(\mathrm{N}=79)\end{array}$ \\
\hline \multicolumn{3}{|l|}{ Crisis management plan } \\
\hline Never accessed & $12(16.0)$ & $13(16.5)$ \\
\hline $1 \mathrm{x}$ accessed & $16(21.3)$ & $12(15.2)$ \\
\hline $2 \mathrm{x}$ accessed & $21(28.0)$ & $14(17.7)$ \\
\hline $3 \mathrm{x}$ accessed & $5(6.7)$ & $21(26.6)$ \\
\hline$>3 \mathrm{x}$ accessed & $21(28.0)$ & $19(24.1)$ \\
\hline Times crisis management plan accessed $(n=129)$ & $3.49 \pm 3.15 ; 2$ & $3.88 \pm 3.78 ; 3$ \\
\hline \multicolumn{3}{|l|}{ Supportive monitoring } \\
\hline Never used & $3(4.0)$ & $7(8.9)$ \\
\hline$<50 \%$ surveys answered & $14(18.7)$ & $15(19.0)$ \\
\hline $50 \%$ to $80 \%$ surveys answered & $17(22.7)$ & $11(13.9)$ \\
\hline$>80 \%$ surveys answered & $41(54.7)$ & $46(58.2)$ \\
\hline $\begin{array}{l}\text { Nine out of } 13 \text { surveys answered during the first } 26 \\
\text { weeks of intervention }^{\text {a }}\end{array}$ & $47(62.7)$ & $57(72.2)$ \\
\hline Number of monitoring surveys answered & $17.05 \pm 8.41 ; 21$ & $17.21 \pm 8.67 ; 21$ \\
\hline Percent monitoring surveys answered & $68.92 \pm 32.76 ; 84$ & $68.68 \pm 34.60 ; 84$ \\
\hline \multicolumn{3}{|l|}{ Internet discussion forum } \\
\hline At least one post submitted & $20(26.7)$ & $18(22.8)$ \\
\hline \multicolumn{3}{|l|}{ Online expert chats ${ }^{\mathrm{b}}$} \\
\hline Never used & -- & $64(81.0)$ \\
\hline At least one group chat attended & -- & $15(19.0)$ \\
\hline At least one individual chat attended & -- & $4(5.1)$ \\
\hline
\end{tabular}


Table ST5: Parameter estimates for specific contrasts of the primary outcome at 12, 20, and 24 months post-randomization

\begin{tabular}{|c|c|c|c|}
\hline & Estimate $(\mathrm{RR}, \mathrm{OR})^{\mathrm{a}}$ & $95 \% \mathrm{CI}$ & $\mathrm{p}$ \\
\hline \multicolumn{4}{|l|}{ SUMMIT } \\
\hline \multicolumn{4}{|l|}{24 months evaluation / primary endpoint: } \\
\hline SUMMIT vs TAU & 0.48 & $0.23,0.98$ & 0.04 \\
\hline Unwell to well & 1.44 & $0.83,2.50$ & 0.19 \\
\hline Well to unwell & 0.69 & $0.44,1.09$ & 0.11 \\
\hline \multicolumn{4}{|l|}{20 months evaluation: } \\
\hline SUMMIT vs TAU & 0.40 & $0.19,0.83$ & 0.01 \\
\hline Unwell to well & 1.53 & $0.88,2.64$ & 0.13 \\
\hline Well to unwell & 0.61 & $0.37,1.00$ & 0.05 \\
\hline \multicolumn{4}{|l|}{12 months evaluation / post-intervention: } \\
\hline SUMMIT vs TAU & 0.48 & $0.21,1.11$ & 0.09 \\
\hline Unwell to well & 1.89 & $1.04,3.44$ & 0.04 \\
\hline Well to unwell & 0.91 & $0.51,1.64$ & 0.74 \\
\hline \multicolumn{4}{|l|}{ SUMMIT-PERSON } \\
\hline \multicolumn{4}{|l|}{24 months evaluation / primary endpoint: } \\
\hline SUMMIT-PERSON vs TAU & 0.62 & $0.31,1.24$ & 0.18 \\
\hline Unwell to well & 1.47 & $0.87,2.51$ & 0.15 \\
\hline Well to unwell & 0.92 & $0.59,1.43$ & 0.70 \\
\hline \multicolumn{4}{|l|}{20 months evaluation: } \\
\hline SUMMIT-PERSON vs TAU & 0.58 & $0.29,1.19$ & 0.14 \\
\hline Unwell to well & 1.59 & $0.93,2.71$ & 0.09 \\
\hline Well to unwell & 0.93 & $0.58,1.49$ & 0.76 \\
\hline \multicolumn{4}{|l|}{12 months evaluation / post-intervention: } \\
\hline SUMMIT-PERSON vs TAU & 0.58 & $0.26,1.32$ & 0.20 \\
\hline Unwell to well & 1.90 & $1.06,3.41$ & 0.03 \\
\hline Well to unwell & 1.11 & $0.63,1.95$ & 0.72 \\
\hline
\end{tabular}

Note: ${ }^{a} \mathrm{RR}=$ Relative ratios for transitions from unwell to well, and well to unwell states.

$\mathrm{OR}=$ Odds ratios for combined states (italicized). 
Table ST6. Open-ended feedback of study participants in the SUMMIT and SUMMIT-PERSON groups

Participant\#1 (SUMMIT-PERSON):

"First up, I wish to thank all of you for your ongoing support. I think this project is important. Without it I wouldn't have come thus far. One suggestion that I'd like to make is to make the monitoring surveys more personal, for instance, to provide space for personal notes. The expert group chats were a great offer, although I did not have the time to use them as often as I wanted to. Overall, I am happy that I engaged in this project. I always felt well accompanied and in good hands, everyone was helpful and caring. One suggestion that I have is that all participants should be given access to all features of this program in the future. Hope this service stays alive, and many more people get involved."

\section{Participant\#2 (SUMMIT):}

"I think this program could be helpful for other patients as well. In particular, the regularity of the monitoring system supports early coping with upcoming crises. Unfortunately, for me the schedule of the monitoring surveys did not always fit with my day structure, that's why I couldn't answer all of them. Thanks to the team and the good luck to all of you!"

\section{Participant\#3 (SUMMIT):}

"You could easily tell that the feedback messages were computer-generated; sometimes I needed more and I felt that this was not enough for me. In addition, especially in shaky times, it could happen that the two-week feedback came too late and you had already gone to seek help. As an adjunct to ongoing outpatient treatment, I found the forum quite helpful, actually more than the monitoring. I was surprised to read that the program ends now, because I thought this would go longer."

\section{Participant\#4 (SUMMIT-PERSON):}

"What I found particularly helpful was to get an immediate feedback after answering the monitoring questions."

\section{Participant\#5 (SUMMIT):}

"Generally, I want to say that the topics covered by the monitoring questions were not broad enough, and they were not always of personal significance for me. Also sometimes I found the response options were not sufficient to express how I really felt. Particularly in the beginning I often received a quite positive feedback, despite the fact that I did not really feel well subjectively. On the other hand, I got a serious feedback just because I had reported suicidal thoughts during the last two weeks. However, the case was that I felt quite ok most of the time during these two weeks, with suicidal thoughts occurring only once during a stressful situation.

Moreover, I have to say that I accessed the crisis management plan only a few times out of curiosity, and I did not feel the energy to actively participate in the Forum. Nevertheless, I think that both are very good concepts. If I had been in that group, I would have liked to attend the expert chats. Overall, despite my critical comments what I really enjoyed most was getting contacted on a regular basis. This helped me keeping an eye on my condition, and to continue to work on my personal recovery. It simply gave me a good feeling to know that there is someone who cares and who intervenes in times I probably can't."

\section{Participant\#6 (SUMMIT-PERSON):}

"The program is helpful in so far, as hospitals usually do not provide any aftercare treatment. All of a sudden, after inpatient treatment has ended, you find yourself left alone without any professional contact. In this situation, the program helped me very, very, much. Of course, it would be preferable if the hospital had provided aftercare. However, as long as this is not the case, programs like this can help and buffer this transition." 